\title{
Entre o vestir e o proteger: os circuitos da economia urbana na indústria de confecção em tempos de pandemia de Covid-19, em Fortaleza- Ceará
}

Entre vestir y proteger: los circuitos de la economía urbana en la industria de la ropa en Covid-19 pandemia times en Fortaleza-Ceará

Between dressing and protecting: the circuits of the urban economy in the clothing industry in Covid-19 pandemic times in Fortaleza-Ceará

Entre pansement et protection: les circuits de l'economie urbaine dans $l$ 'industrie du vêtement en temps de pandémie Covid-19 à Fortaleza-Ceará.

Marlon Cavalcante Santos, José Borzacchiello da Silva e Eciane Soares da Silva Bezerra

\section{OpenEdition}

\section{Journals}

\section{Edição electrónica}

URL: https://journals.openedition.org/espacoeconomia/19038

DOI: 10.4000/espacoeconomia.19038

ISSN: 2317-7837

Editora

Núcleo de Pesquisa Espaço \& Economia

\section{Refêrencia eletrónica}

Marlon Cavalcante Santos, José Borzacchiello da Silva e Eciane Soares da Silva Bezerra, «Entre o vestir e o proteger: os circuitos da economia urbana na indústria de confecção em tempos de pandemia de Covid-19, em Fortaleza-Ceará », Espaço e Economia [Online], 21 | 2021, posto online no dia 12 julho 2021, consultado o 17 julho 2021. URL: http://journals.openedition.org/espacoeconomia/ 19038 ; DOI: https://doi.org/10.4000/espacoeconomia.19038

Este documento foi criado de forma automática no dia 17 julho 2021.

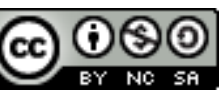

Espaço e Economia - Revista brasileira de geografia econômica est mise à disposition selon les termes de la licence Creative Commons Attribution - Pas d'Utilisation Commerciale - Partage dans les Mêmes Conditions 4.0 International. 


\section{Entre o vestir e o proteger: os} circuitos da economia urbana na indústria de confecção em tempos de pandemia de Covid-19, em Fortaleza-Ceará

Entre vestir y proteger: los circuitos de la economía urbana en la industria de la ropa en Covid-19 pandemia times en Fortaleza-Ceará

Between dressing and protecting: the circuits of the urban economy in the clothing industry in Covid-19 pandemic times in Fortaleza-Ceará

Entre pansement et protection: les circuits de l'economie urbaine dans $l$ 'industrie du vêtement en temps de pandémie Covid-19 à Fortaleza-Ceará.

Marlon Cavalcante Santos, José Borzacchiello da Silva e Eciane Soares da Silva Bezerra

\section{Introdução}

1 A indústria de confecção em Fortaleza é responsável por uma produção significativa de vestimentas, tanto para o mercado local, regional e até o internacional. Esse ramo produtivo está espalhado por todo o município da capital cearense, principalmente nos bairros periféricos com baixo IDH (Índice de Desenvolvimento Humano).

Peças do vestuário como: camisas, bermudas, calças, entre outras são as principais mercadorias da produção da indústria de confecção. No novo contexto de pandemia de Coronavírus, na qual tem como uma das consequências a Covid-19 ${ }^{1}$, a indústria de confecção, predominantemente inserida no circuito inferior da economia, é procurada por seguimentos do Estado, entre outras instituições públicas e privadas, as mesmas 
inseridas no circuito superior para a produção de máscaras em busca da contenção da transmissão da Covid-19 vista à falta de 'EPI's.

3 Para o entendimento dos circuitos da economia urbana é necessário saber que foram concebidos e propostos pelo professor Milton Santos, nos anos 1970. Para (Santos, 2008, [1979]), sistema urbano se constitui por dois subsistemas, o circuito superior e o circuito inferior, o autor afirma:

O circuito superior originou-se diretamente da modernização tecnológica e seus elementos mais representativos hoje são os monopólios. O essencial de suas relações ocorre fora da cidade e da região que os abrigam e tem por cenário o país ou o exterior. $O$ circuito inferior, formado de atividades de pequena dimensão e interessando principalmente as populações pobres, é, ao contrário, bem enraizado e mantém relações privilegiadas com sua região (SANTOS, 2008, p. 22, [1979]).

4 Em um primeiro momento, a definição dos circuitos e suas relações de abrangência foram sugeridas dessa forma, no entanto foram modificando-se com alterações das novas condições técnicas, econômicas e sociais da contemporaneidade, resultando em novas relações entre os circuitos e a escala de abrangência, nos ramos de produção e nas conjunturas espaciais urbanas.

5 Assim sendo, os circuitos da economia urbana superior e inferior faz-se necessário para o entendimento da estruturação e dinâmica da indústria de confecção em FortalezaCeará.

6 O circuito superior seria o resultado direto da modernização capitalista, sendo ele responsável pelo gerenciamento de capital, financiamento, articulações com governos e instituições financeiras; lucro por montante de mercadorias vendidas, entre outras características do circuito.

7 Já o circuito inferior está relacionado à pequena atividade de sobrevivência de uma população pobre, que muitas vezes parece estar à margem do processo de inserção total do capital chamado "regular", que vive de pequenos bicos, produz e/ou comercializa para a sobrevivência e obtém lucro por peças vendidas, a principal fonte de renda.

do exposto, será feito uma análise sobre as novas dinâmicas produtivas da indústria de confecção, dentro do circuito inferior da economia, na qual foi "solicitada" para a produção de máscaras pelo circuito superior, no enfrentamento da proliferação da infecção de Coronavírus, no espaço urbano de Fortaleza. Evidencia-se, desse modo, a relação entre os dois circuitos da economia.

Os dois circuitos são resultados da modernização, no circuito superior o resultado é direto, já o inferior apresenta-se de forma indireta. A existência dos mesmos se dá pela interação e articulação travada nos ramos econômicos e no espaço urbano, havendo uma relação constante de "solicitação" entre os dois circuitos para a existência de um espaço urbano em países subdesenvolvidos. (SANTOS, 2008, [1979]), (SILVEIRA, 2009) afirmam que o espaço urbano em países subdesenvolvidos é construído pela interação entre os dois circuitos ${ }^{3}$.

Como procedimentos metodológicos foi feita pesquisa bibliográfica sobre a temática (teoria espacial dos circuitos da economia urbana, dados referentes a infecções de Covid-19, localização de casos dado doença, entre outros), análises em documentos fornecidos pela Prefeitura de Fortaleza, produções acadêmicas do Programa de Pós Graduação em Geografia da Universidade Federal do Ceará (UFC) e do Observatório das Metrópoles- Núcleo Fortaleza, publicações em jornais locais e em mídias sociais 
(reportagens e notícias), boletins epidemiológicos do IntegraSUS ${ }^{4}$-SESA-Ceará entre outras instituição.

11 A publicação de dados e alguns mapas foram feitos baseados em documentos produzidos pela Secretaria de Saúde do respectivo município, tratando-se de dados secundários sobre a saúde.

\section{INDÚSTRIA DE CONFECÇÕES EM FORTALEZA}

12 A indústria de confecção é um ramo significativo no município de Fortaleza, o Censo das Confecções $(2008)^{5}$ afirma que existem 2.782 unidades produtivas no Ceará, das quais 1.962 concentram-se em Fortaleza. Essa informação foi baseada em dados da Secretaria da Fazenda do Ceará (Sefaz-CE) de 2007 e do banco de dados do Sistema Integrado da Arrecadação (Siga).

A concentração confeccionista em Fortaleza é significativa para o Ceará, pois enquanto outras cidades do estado têm um percentual de $29,48 \%$ das unidades produtivas confeccionistas, $70,52 \%$ das confecções estão concentradas na capital, e se forem levadas em consideração outras cidades da RMF, como Caucaia, Maracanaú, Maranguape e Pacatuba, esse percentual aumenta consideravelmente.

Diante disso, evidencia-se a predominância do percentual desse tipo de indústria na capital cearense. No mapa 1, mostra-se a localização das indústrias de confecções no município de Fortaleza.

Mapa 1-Mapa de localização da indústria de confecção e centros comerciais em Fortaleza- Ceará.

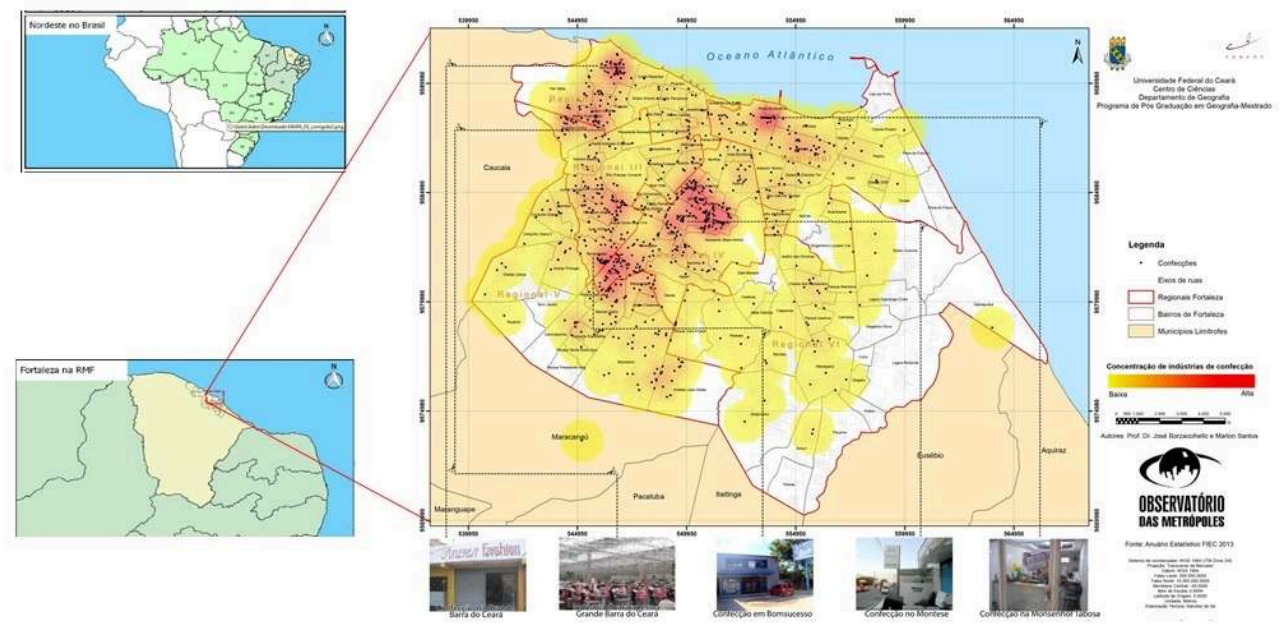

Fonte: Os autores (2021).

Observando o mapa 1, constata-se que a indústria de confecção em Fortaleza espalha-se por todo o município, com uma maior frequência nas áreas sudoeste e noroeste da capital. As áreas compreendidas pelas Regionais ${ }^{6} \mathrm{I}$ e V, bairros como Barra do Ceará, Goiabeiras, Quintino Cunha, na Regional I; e em bairros como Parque Santa Rosa, Canidezinho, Bom Jardim e outros bairros pertencentes a Regional V.

Na regional IV, verifica-se uma concentração significativa dessa indústria nos bairros Montese, Parreão, Damas e Serrinha, muitas indústrias ligadas ao comércio de loja de fábrica da Avenida João Pessoa. 

domiciliar dispõe de equipamentos e insumos (tecidos, linhas, aviamentos, elásticos, entre outros) necessários à produção confeccionista existente nas fábricas. Essa fabricação foi incentivada por créditos financeiros para os produtores domiciliares de confecção, já que em torno de $80 \%$ das fábricas de confecção estão na casa do trabalhador (CAVALCANTE SANTOS, 2014, 2017), construindo um fenômeno no espaço urbano na qual (LENCIONI, 1996) denomina de Fábrica Camuflada ${ }^{7}$, pois as fábricas de confecção estão majoritariamente dentro da casa do trabalhador. existe circuito inferior. Os dois circuitos estão imbricados um no outro. Retoma-se aqui a afirmação de (SANTOS, 2008, [1979]) de que eles são complementares e não duais, são concorrentes, mas ao mesmo tempo são interdependentes, e constroem um complexo no espaço urbano, estando inserida a indústria de confecção em Fortaleza-Ceará.

Dentro dos circuitos da economia urbana proposto pelo professor (SANTOS, 2008, [1979]) insere-se o universo produtivo confeccionista. Geralmente, o gerenciamento, a pesquisa, o setor financeiro fica dentro da firma, ou seja, na chamada marca, que não necessariamente tem produção, pois a produção é terceirizada para a facção (CAVALCANTE SANTOS, 2014, 2017). 
Diante do exposto, Fortaleza tem uma indústria de confecção significativa inserida dentro do circuito inferior da economia urbana, sendo a mesma bem articulada com o circuito superior, pois entre produção, gerenciamento, circulação há uma conexão intensa e dependente. No entanto, com etapas definidas, resultando na presença intensa do circuito inferior na indústria de confecção, na casa do trabalhador, ou em alguns pequenos galpões produtivos e a venda centrada no circuito superior em shoppings como Maraponga Mart Moda, Centro Feshion entre outros estabelecimentos (SILVA, 2018).

\section{QUANDO O VESTIR SE TORNA PROTEÇÃO}

No Ceará, o município de Fortaleza foi o centro dispersor dos casos de contaminação pela Covid-19. No mês de março, Fortaleza já apresentava os primeiros casos de Covid-19 no Ceará. No princípio, localizado em bairros de classe média alta e com alto IDH, como Meireles, Aldeota, Dionísio Torres, Luciano Cavalcante entre outros. No decorrer das semanas seguintes e no mês de maio, o processo de contaminação se espalha pelo território do município, chegando a praticamente todos os bairros da cidade.

Em maio, Fortaleza vive o pico da pandemia, com UPA's (Unidade de Pronto Atendimento) lotadas, hospitais de referência como: Hospital São José, Hospital do Coração de Messejana, IJF (Instituto José Frota), Frotinhas, HGF (Hospital Geral de Fortaleza) e hospitais particulares com taxas de praticamente cem por cento de UTI's (Unidade de Terapia Intensiva) e enfermarias ocupadas. No gráfico 1, produzido pela Prefeitura de Fortaleza observa-se a evolução da pandemia em Fortaleza.

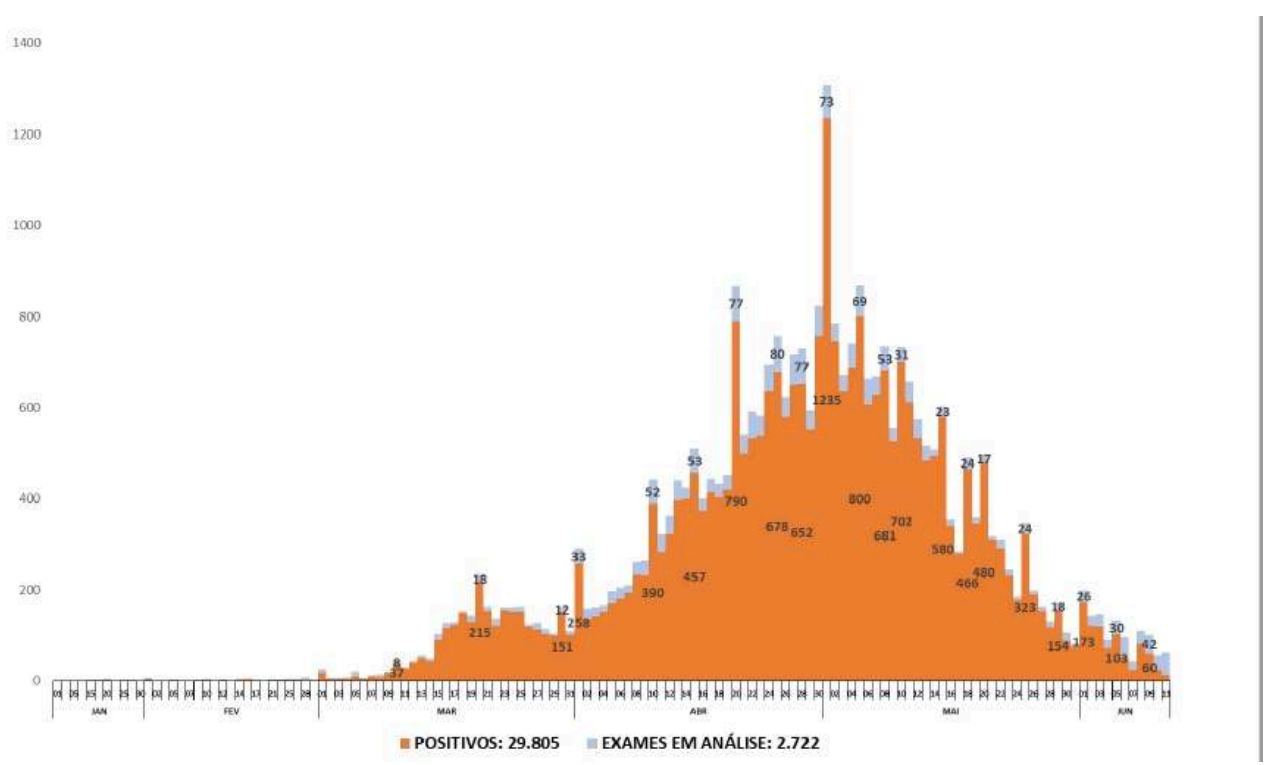

Gráfico 1-Covid-19: Série temporal de casos confirmados e número de exames em análise (RT-PCR para SARS-CoV-2) no LACEN/CE e laboratórios privados. Fortaleza, 2020.

FONTE: Integra SUS/ Indicadores/SESA- COVID-19- Atualizado em 12 de junho de 2020, às 09:30 h.

Pelo gráfico 1 elaborado pela SMS (Secretaria Municipal de Saúde/PMF) observa-se que a doença começa no início de março com evolução gradual nos meses de abril e chegando a um alto nível de contágio no mês de maio, fazendo o poder público, 
Governo do Estado do Ceará e Prefeitura de Fortaleza (PMF) suspender atividades econômicas e serviços públicos na tentativa de diminuir os casos de dispersão da doença. Por meio de decretos ${ }^{8}$ estaduais e municipais é implantado o lockdown ${ }^{9}$ como uma das medidas para contenção da doença.

Como mostrado no gráfico 1, a dispersão da Covid-19 se dar de uma forma rápida em questão de dias, praticamente do mês de março para abril o município já tem o pico de infecções. A primeira fase da doença, chamada de primeira onda, assola os bairros que tem mais infraestrutura e setores sociais com maior poder de renda. Evidencia-se na primeira fase da doença, bairros como Meireles e Aldeota como os locais dispersores da Covid-19 para outros bairros da cidade.

Diante dessa condição há a pressão no sistema de saúde público e privado, existindo uma procura demasiada por insumos como máscaras, óculos de proteção, batas para a proteção contra o novo Coronavírus, fazendo que o próprio sistema público de saúde tenha dificuldade em comprar esses EPI's ${ }^{10}$ e faltando os mesmos para serem encontrados em farmácias e em comércio de ramo especializado desses materiais.

31 Em pesquisa realizada em jornais locais teve-se acesso a informações sobre o projeto denominado Todos com Máscara. Segundo reportagens, a PMF selecionou bairros com baixo IDH (Índice de Desenvolvimento Humano) para a implantação do projeto, fornecendo o insumo e pagamento para os profissionais de costura no valor de R\$ 360,00 reais para os chamados trabalhadores autônomos e R\$14.760 para microempresas, buscando a produção de 1,5 milhões de máscaras (CÂMARA MUNICIPAL DE FORTALEZA, 2019).

Muitos trabalhadores devido ao momento da pandemia diminuíram sua produção, ou pararam de produzir, sem esquecer que praticamente esses trabalhadores ganham por peças produzidas no fluxo normal do processo produtivo. Com a situação de calamidade, a renda foi prejudicada ou deixou de existir, assim esse projeto buscou manter a renda mínima desses trabalhadores.

O poder público sabendo da capacidade que Fortaleza tem no segmento de confecção com maquinário instalado, mão de obra qualificada para a produção, construiu esse projeto como alternativa a garantir renda mínima e proteção a uma parte da população com distribuição de máscaras. Na figura 1, mostra-se produção de máscaras por uma costureira.

Figura 1-Costureira produzindo máscara na indústria de confecção.

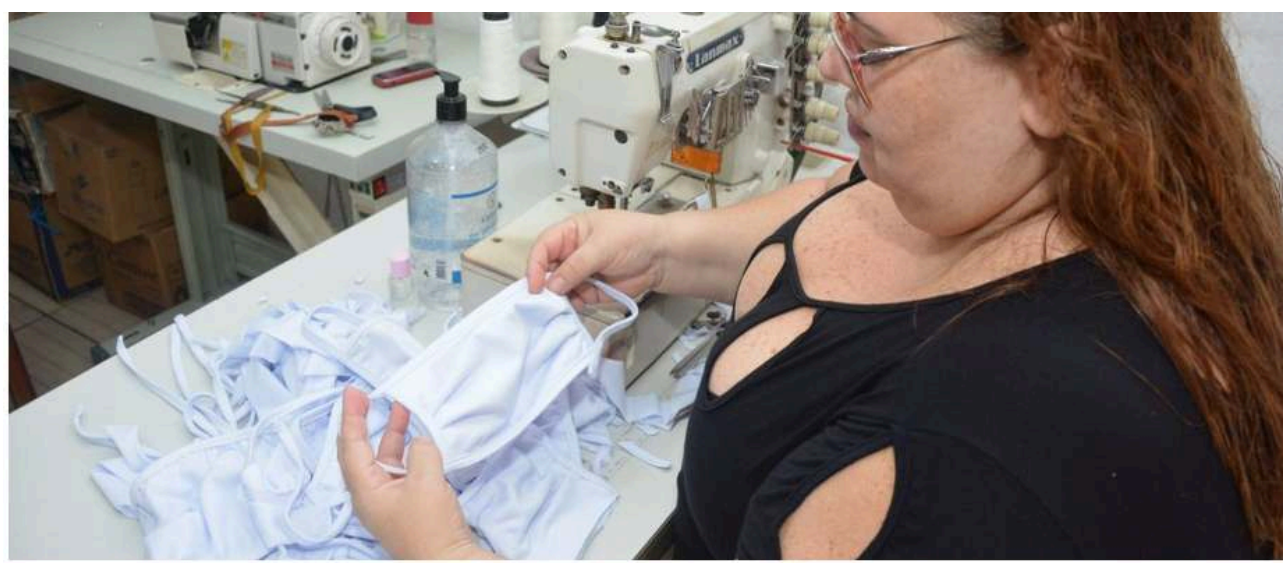


FonTE: Érika Fonseca, Câmara Municipal de Fortaleza (2020).

Importante ressaltar que a indústria de confecção em Fortaleza tem características importantes como: emprego de mão de obra feminina e a localização em bairros oeste da cidade, esses periféricos, estando as fábricas de confecção dentro da casa da trabalhadora(o)r.

A mulher, geralmente, nesse ramo produtivo tem uma dupla função: fabricante e dona de casa, pois suas condições por muito tempo estiveram ligadas ao êxito da família, notadamente tendo o cuidado com marido e com filhos, assim como trabalhando com a costura. Essas trabalhadoras continuam tendo as mesmas obrigações com os maridos, filhos e as demais atividades domésticas, articulando-se entre o trabalho doméstico e a fábrica domiciliar de confecção, na qual a máquina de costura faz parte do imobiliário doméstico (SILVA, 1992).

A mulher tem no trabalho doméstico uma das formas de ajudar no orçamento familiar. Ela fica em casa passando, lavando roupas, preparando alimentos, entre outras atividades cotidianas, enquanto o homem vai procurar trabalho fora de casa. As filhas mais novas, geralmente, ficam ajudando a mãe em casa, enquanto as mais velhas trabalham fora do ambiente doméstico.

Muitas dessas mulheres são chefes de família, muitas vezes têm a função de prover diretamente o sustendo do núcleo familiar. (MACHADO DA SILVA, 1979). Analisando as condições de trabalho em domicílio, considera esse trabalho como atividades de lida com a casa e com trabalho feminino em domicílio remunerado. No caso, a costura é uma forma de a mulher encarar uma dupla jornada cotidiana.

Além dos afazeres domésticos exercidos, ela atua em atividades complementares por meio da costura. A máquina de costura adentra o domicílio e "[...] ocupa espaço de destaque no imobiliário doméstico" (SILVA, 2008, p. 138), possibilitando uma atividade importante para a composição da renda familiar.

Diante da articulação familiar presente para garantir o sustento diário e localização em bairros periféricos de Fortaleza, o poder estatal buscou alternativas para garantir renda e produção de máscaras de proteção para a população local, mostrando-se uma articulação entre os dois circuitos da economia urbana na capital cearense.

2 Muitas vezes essa indústria não é vista na cidade, sendo a indústria invisível (CAVALCANTE SANTOS, 2014) e como ressaltado por (LENCIONI, 1996) dentro dos labirintos do urbano que a indústria de confecção está presente, fazendo da cidade o espaço em que a produção tem lugar privilegiado. A cidade é o espaço da produção, estando ela privilegiada no modo de produção capitalista.

3 Dentro desse contexto, insere-se o projeto Todos de Máscara, o qual tem como prérequisitos os bairros que apresentam baixo IDH. Localidades com baixo IDH, geralmente, tem pouca infraestrutura, grande parte da população vive de atividades no circuito inferior da economia, condições sanitárias insuficientes, especialmente o saneamento básico.

4 Muitas vezes, a escassez de água, entre outros problemas, aumenta a possibilidade de contaminação e adoecimento, exemplo desses bairros são: Barra do Ceará, Jardim 
Iracema, Quintino Cunha, Bonsucesso, Parque Santa Rosa, Dom Lustosa, entre outros, todos localizados nas áreas oeste de Fortaleza.

Os mapas 2 e 3 a seguir mostram, respectivamente, a distribuição de casos de Covid-19 e óbitos decorrentes da doença em bairros no município de Fortaleza.

Mapa 2- COVID-19: Distribuição dos casos por bairro de residência dos pacientes, Fortaleza, 2020*.

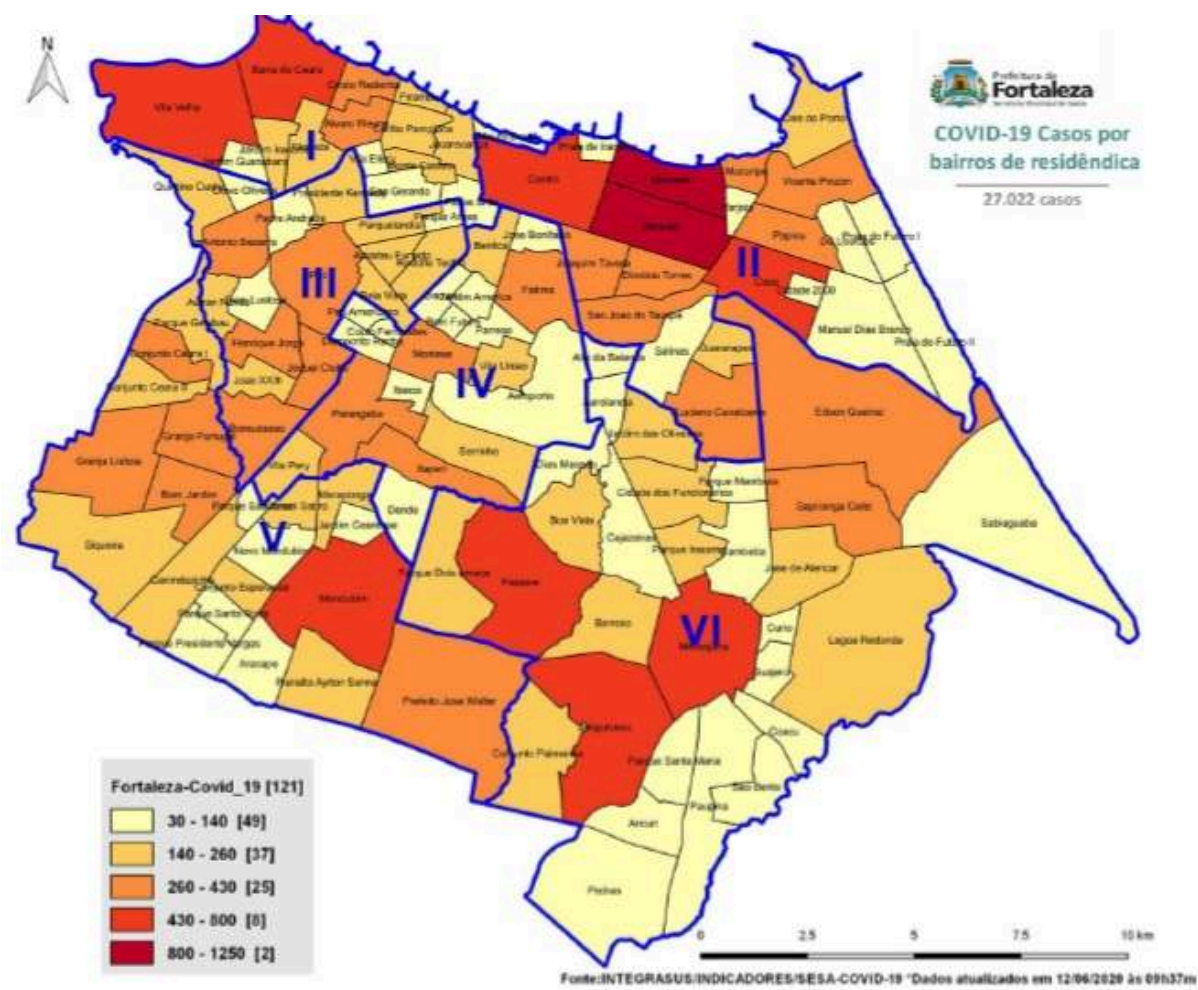

O mapa 3 apresenta a densidade de óbitos por Covid-19 em Fortaleza. 


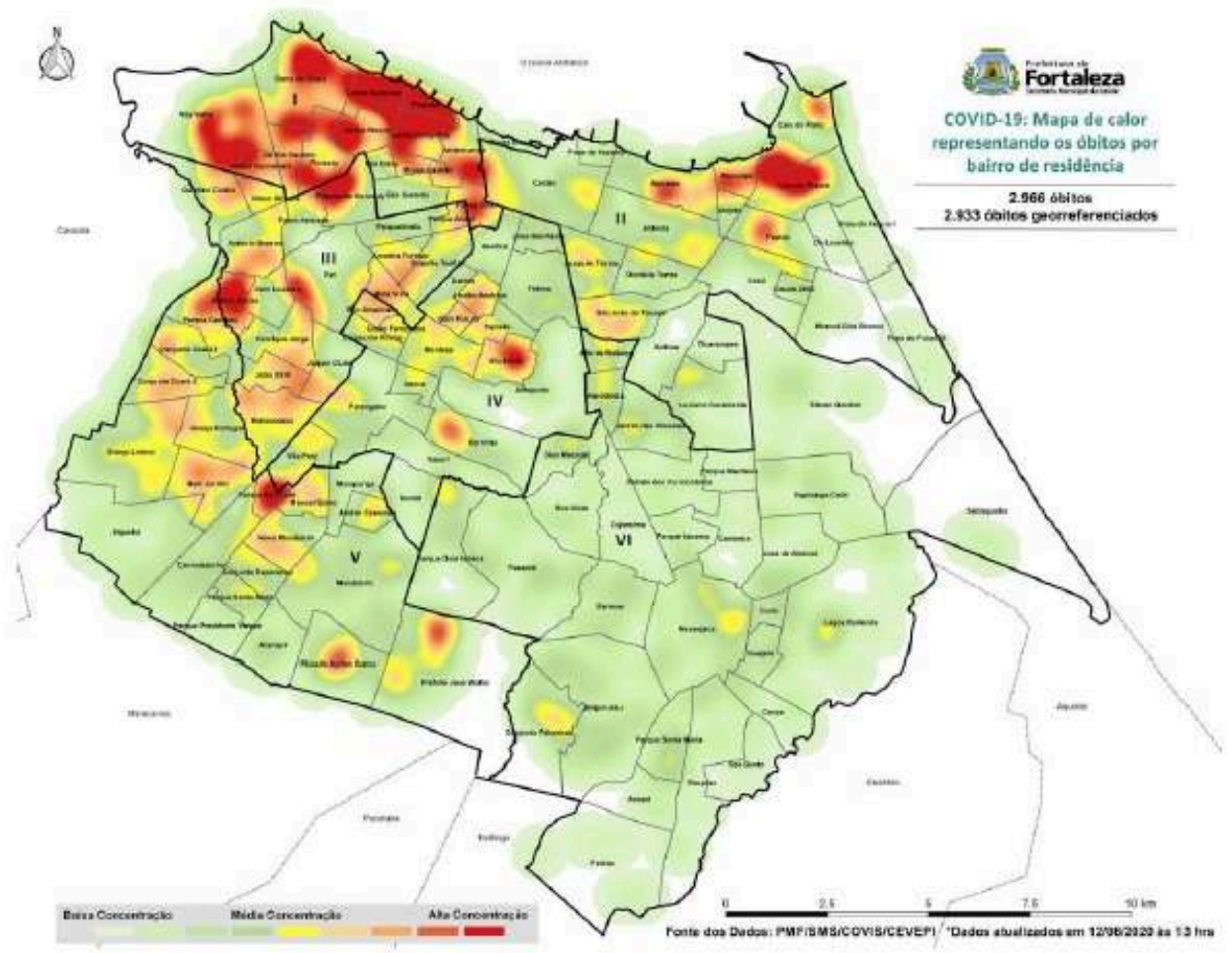

Mapa 3-COVID-19: Densidade espacial dos óbitos acumulados. Fortaleza, 2020.

Fonte: SMS Fortaleza - COVID-19 - Atualizado 12 de junho de 2020, às $11 \mathrm{~h}$.

Na comparação entre os dois mapas 2 e 3, percebe-se que, de um modo geral, as maiores concentrações de óbitos no município de Fortaleza coincidem com os bairros de baixo IDH, onde também estão as indústrias de confecção. Expressiva parte dessa população tem muitas dificuldades para ter acesso a bens e serviços básicos para garantia da sobrevivência.

Segundo o estudo da SMS da Prefeitura de Fortaleza, bairros como Barra do Ceará com 728 casos de contaminação e 107 óbitos; Vila Velha com 355 casos de contaminação e 89 óbitos; Cristo Redentor com 264 casos e 66 óbitos; Granja Lisboa 264 casos e 73 óbitos; entre outros bairros periféricos que concentram os números de óbitos.

Para Pequeno (2009) grande parte da população de Fortaleza estar inserida nas categorias socioespaciais de inferior ${ }^{11}$ e popular periférica. Essas categorias têm uma mão de obra predominantemente de cor preta, com baixo nível de escolaridade. Mesmo nessas tipologias, o gênero feminino tem pouco acesso aos empregos ofertados. Nos Gráficos 1 e 2 a seguir, faz um comparativo entre casos e óbitos de Covid-19 em alguns bairros de Fortaleza. 
Gráfico 1: relação infecção por Covid-19 e número de óbitos em bairros com baixo IDH.

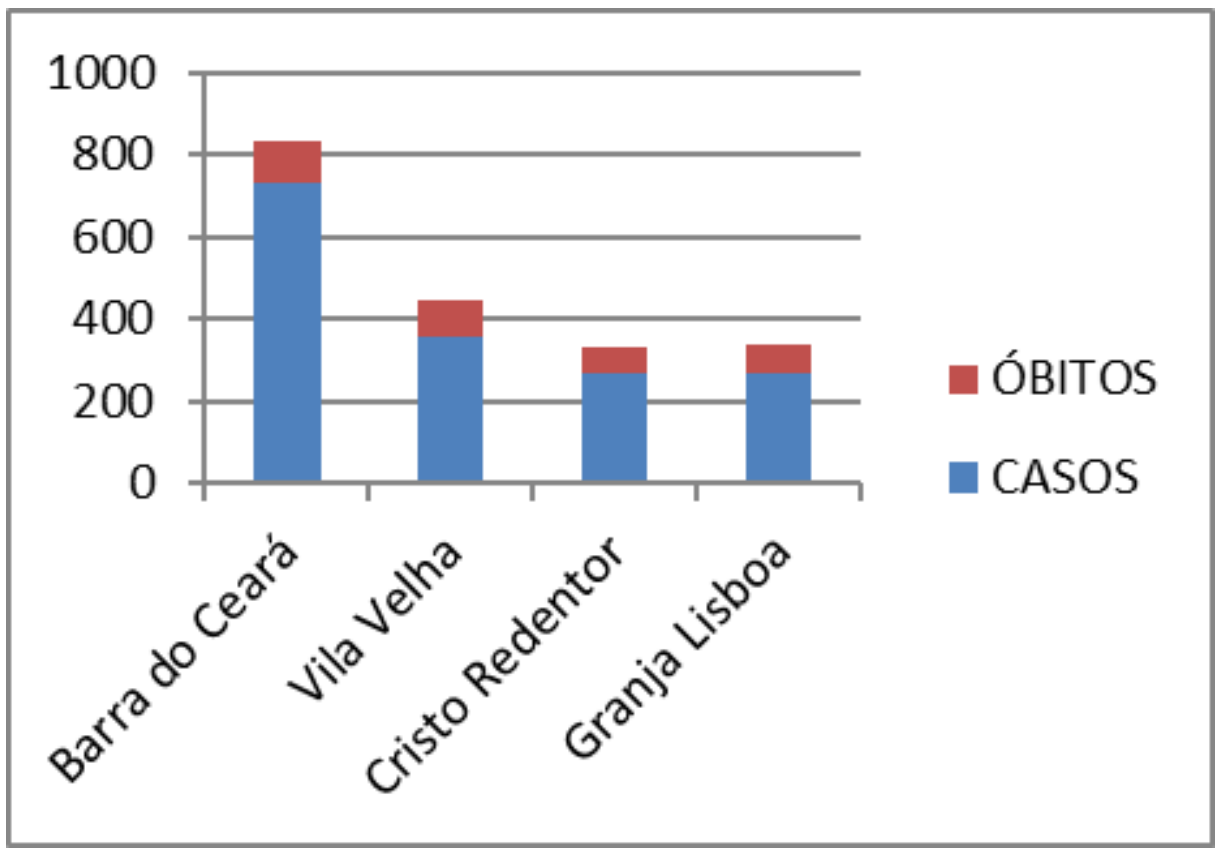

FONTE: Secretaria Municipal da Saúde- Prefeitura de Fortaleza (2020).

Gráfico 2: relação infecção por Covid-19 e número de óbitos em bairros com alto IDH.

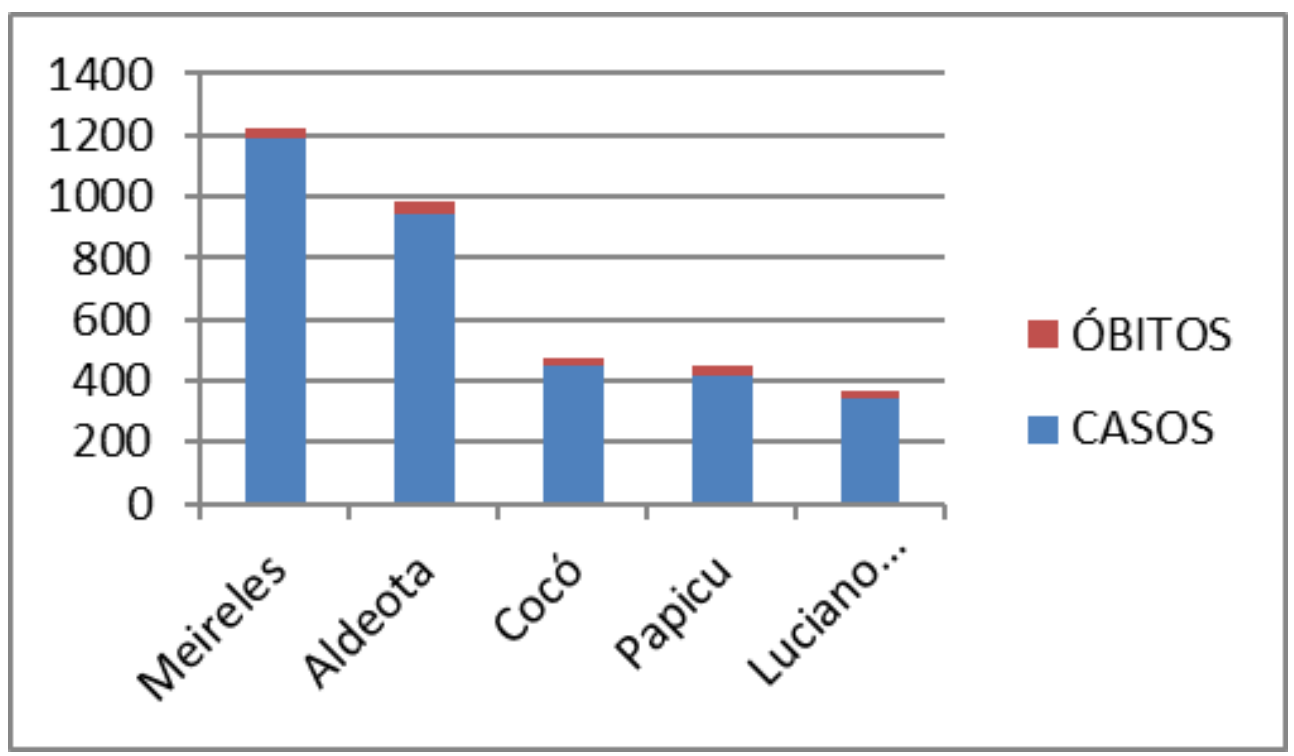

FONTE: Secretaria Municipal da Saúde- Prefeitura de Fortaleza (2020).

Como se pode constatar, a maioria dos óbitos está centrada nos bairros pobres da cidade que coincide onde estão as fábricas de confecção domiciliar, no território municipal. São nessas áreas onde estão trabalhadores que têm rendimentos de até dois salários-mínimos mensais, assim como mão de obra doméstica, trabalhadores do comércio, catadores entre outras atividades presentes na cidade.

Vê-se nos gráficos 1 e 2, comparando os bairros de baixo IDH da periferia de Fortaleza a bairros de classe média alta e de setores dirigentes, constata-se que há um maior 
número de casos de Covid-19, nos bairros privilegiados. No entanto, já em relação ao número de óbitos, eles são bem menores que os verificados nos bairros periféricos.

Bairros como alto IDH como: Meireles, Aldeota, Cocó, Papicu, Luciano Cavalcante somam uma quantidade significativa de casos, mas com menor número de óbitos. Segue respectivamente o número de casos: 1.193, 946, 452, 420, 345, óbitos: 26, 40, 19, 31, 18.

Dentro desse contexto, projeto Todos de Máscaras, o Estado em seu nível municipal se articula com produtores, que em outros momentos estão na economia chamada de informal, essa que é apenas um aspecto do circuito superior da economia urbana, e ao mesmo tempo há a articulação com empresas de confecção que geralmente estão inseridas na economia dita formal, no circuito superior.

Em meio à pandemia, a importante indústria de confecção em Fortaleza muda sua produção, ao invés de fabricar a vestimenta se volta para produção de máscara, estando essa produção articulada entre os circuitos superior e inferior da economia urbana.

Assim, na dinâmica do espaço urbano, as atividades dos circuitos da economia urbana, circuito inferior e circuito superior, estão articulados entre poder público e os chamados "trabalhadores autônomos". No atual contexto, a indústria de confecção que está inserida de forma preponderante no circuito inferior se articula de maneira mais intensa com instituições do circuito superior na busca da maior produção de máscaras para o enfrentamento da pandemia de Covid-19.

\section{CONSIDERAÇÕES FINAIS}

60 O ramo produtivo da confecção espalhado por todo o município da capital cearense, principalmente na periferia, possui relevância na geração de renda e ocupação. Essa indústria de confecção significativa como pontuamos é inserida dentro do circuito inferior da economia urbana, sendo a mesma bem articulada com o circuito superior através de uma conexão intensa e dependente que vai desde a produção até a circulação.

61 Em face da situação de pandemia de Covid-19, o Estado lançou diversos incentivos para o aproveitamento do maquinário e da indústria de confecção instituída em Fortaleza.

62 Esses incentivos voltaram-se para a produção de máscara de pano para a proteção da população, no sentido de amenizar a escassez de equipamentos de proteção individual como as máscaras, diante da demanda tanto pelos hospitais como pela população em geral em busca de proteção.

63 Assim, houve o incentivo à produção de máscaras para serem distribuídas para vários setores da população, garantindo o sustento diário de muitas famílias de bairros periféricos de Fortaleza. Destacamos ainda que essa articulação entre o poder estatal que buscou alternativas para garantir renda a partir da produção de máscaras de proteção para a população local, evidencia uma articulação entre os dois circuitos da economia urbana na capital cearense. 


\section{BIBLIOGRAFIA}

CAVALCANTE SANTOS. M, C. Um estudo dos circuitos da economia urbana na indústria confeccionista do Ceará, Rio Grande do Norte, Pernambuco e Bahia. Tese. Universidade Federal do Ceará, Fortaleza, 2017.

CAVALCANTE SANTOS. M, C. A dinâmica dos circuitos da economia urbana na indústria de confecção em Fortaleza-Ceará. Dissertação. Universidade Federal do Ceará, Fortaleza, 2014.

BEZERRA, E.S. O mercado metropolitano de confecção nos circuitos da economia urbana de Fortaleza-Ceará. Tese. Universidade Federal do Ceará, Fortaleza, 2018.

FORTALEZA. Coordenadoria de Vigilância em Saúde - Célula de Vigilância Epidemiológica. SMSprefeitura Municipal de Fortaleza. Informe Semanal COVID-19. 2020. Disponível em: https:// www.fortaleza.ce.gov.br/noticias/prefeitura-de-fortaleza-divulga-boletim-epidemiologicosemanal-da-covid-19. Acesso em: 18 jun. 2020.

FORTALEZA. Cleonardo Dias. Câmara Municipal de Fortaleza. Covid-19: Projeto Todos com Máscaras irá produzir mais de 1,5 milhão de máscaras. 2020. Disponível em: https:// www.cmfor.ce.gov.br/2020/04/06/covid-19-projeto-todos-com-mascaras-ira-produzir-maisde-15-milhao-de-mascaras. Acesso em: 17 jun. 2020.

LENCIONI, S. A reestruturação da indústria têxtil em São Paulo. v. 10. Rev do Dep. de Geografia da USP. São Paulo, 1996.

MACHADO DA SILVA, L. A. Notas sobre os pequenos estabelecimentos comerciais. In. (org.) Lopes, J. Silva, L. Alvin, M. Durão, J. Marin, M. Teixeira, A. Reprodução da Subordinação. Mudança Social no Nordeste. Rio de Janeiro: Paz e Terra. 1979.

PEQUENO, L. R. Estrutura intraurbana socioocupacional e condição desigual de moradia na Região Metropolitana de Fortaleza. In: DANTAS, E.W. COSTA, M.C.L. Vulnerabilidade Socioambiental na Região Metropolitana de Fortaleza. Fortaleza: Edições UFC, 2009. p. 55- 136.

SANTOS, M. O Espaço Dividido: Os dois circuitos da Economia Urbana dos Países Subdesenvolvidos.2 ed. São Paulo, EdUSP, 2008.

SILVA, J. B. Diferenciação socioespacial. Cidades. Presidente Prudente v. 4, n. 6, p. 89-100, 2007. Disponível em: http://revista.fct.unesp.br/index.php/revistacidades/article. Acesso em: 10 mar. 2013.

SILVA, J.B. Adeus Sudene, que Saudade de Celso Furtado. p. 25-32, Mercartor, $n^{\circ}$ 17, vol. 8 , Fortaleza, 2009.

SILVA, J. B. O mercado de trabalho e a cidade brasileira. In: VALENÇA. M.M. (org). Cidade (i)legal. Rio de Janeiro: Mauad X, 2008.

SILVA, J. B.Quando os incomodados não se retiram: uma análise dos movimentos sociais em Fortaleza. Fortaleza: Multigraf, 1992.

SILVA, E. S. Dinâmica Socioespacial do Comércio Popular de Confecção no Centro de Fortaleza. Dissertação. Universidade Federal do Ceará, Fortaleza, 2013.

SINGER, P. Economia Política da Urbanização. 9ªed. São Paulo, ed. Brasiliense, 1983.

SILVEIRA, M. L. Financias, Consumo e Circuito da Economia Urbana na cidade de São Paulo. v. 22. no 55. Rev. CCH, Salvador, 2009. 


\section{NOTAS}

1. A COVID-19 é uma doença causada pelo coronavírus SARS-CoV-2, que apresenta um quadro clínico que varia de infecções assintomáticas a quadros respiratórios graves. De acordo com a Organização Mundial de Saúde (OMS), a maioria dos pacientes com COVID-19 (cerca de 80\%) podem ser assintomáticos e cerca de $20 \%$ dos casos podem requerer atendimento hospitalar por apresentarem dificuldade respiratória e desses casos aproximadamente $5 \%$ podem necessitar de suporte para o tratamento de insuficiência respiratória (suporte ventilatório).

2. Equipamentos de uso individual.

3. Há um terceiro circuito chamado de circuito superior marginal, o qual representa o topo do circuito interior e a base do circuito superior.

4. O Integra SUS são publicações diárias feitas pela Secretaria de Saúde do estado do Ceará SESA com informações sobre médias móveis de infecções, óbitos nos municípios cearenses.

5. Publicação feita pelo Instituto Evaldo Lodi (IEL), pelo Sebrae-CE e pelo Sindicato das Indústrias de Confecções de Roupas e Chapéus de Senhoras no Estado do Ceará (SindConfecções).

6. Divisão administrativa do município de Fortaleza - Regionais 1,2,3,4,5,6 e a Regional do Centro.

7. A indústria de confecção, no caso, recebe a substantivação de "Indústria Camuflada", pois sua identificação enquanto unidade produtiva requer uma observação, por dentro da unidade, já que sua identificação é difícil ser percebida, localizando-se dentro da casa do trabalhador.

8. Decreto no 33.519 , de 19 de março de 2020 , Decreto no 33.521 , de 21 de março de 2020 do Governo do Estado do Ceará e seguido pela PMF.

9. Isolamento social rígido como comércio, fábricas, instituições públicas e privadas fechadas na busca da contenção da dispersão da doença Covid-19.

10. Equipamentos de Proteção Individual.

11. A tipologia inferior abriga a população que vive nas franjas da metrópole ou que ocupa ambientes de rios e lagoas, tratando-se de um conjunto demográfico com alta vulnerabilidade social e ambiental. A tipologia popular periférica se caracteriza por um contingente demográfico que reside em conjuntos habitacionais. Essa tipologia está intensamente ligada à institucionalização de indústrias. Em Fortaleza e na RMF, há um contingente demográfico expressivo no oeste e sul da capital e nos municípios de Maracanaú, Pacatuba, Horizonte e Itaitinga (PEQUENO, 2009).

\section{RESUMOS}

A presente pesquisa é resultado de estudos sobre os circuitos da economia urbana, circuito superior e inferior, na indústria de confecção em Fortaleza-Ceará. Como ramo importante na capital cearense, a indústria de confecção, localizada principalmente na periferia, tem um expressivo número de trabalhadores, principalmente do gênero feminino, tendo local de trabalho suas residências. Analisam-se as modificações que ocorreram neste ramo industrial com a pandemia de Covid-19 e as ações do Estado, principalmente a nível municipal para garantir renda mínima e produção de máscaras para a população local, utilizando para tanto o maquinário e a indústria de confecções instituída em Fortaleza. Como metodologia foi utilizada bibliografia referente à temática, análises de dados secundários, seguindo da produção do presente artigo. 
Esta investigación es el resultado de estudios sobre los circuitos de la economía urbana, superior e inferior, en la industria de la confección en Fortaleza-Ceará. Como rama importante en la capital cearense, la industria de la confección, ubicada principalmente en la periferia, tiene un expresivo número de trabajadores, principalmente mujeres, con sus hogares en el lugar de trabajo. Se analizan los cambios ocurridos en este ramo industrial con la pandemia Covid-19 y las acciones del Estado, principalmente a nivel municipal para garantizar ingresos mínimos y producción de mascarillas para la población local, utilizando la maquinaria y la industria del vestido instituida en Fortaleza. Como metodología se utilizó bibliografía relacionada con el tema, análisis de datos secundarios, seguido de la producción de este artículo.

This research is the result of studies on the urban economy circuits, upper and lower, in the clothing industry in Fortaleza-Ceará. As an important branch in the capital of Ceará, the clothing industry, located mainly on the periphery, has an expressive number of workers, mainly female, with their homes in the workplace. The changes that occurred in this industrial branch with the Covid-19 pandemic and the State's actions are analyzed, mainly at the municipal level to guarantee minimum income and production of masks for the local population, using machinery and the clothing industry instituted in Fortaleza. As methodology, bibliography related to the theme was used, secondary data analysis, followed by the production of this article.

Cette recherche est le résultat d'études sur les circuits économiques urbains, supérieurs et inférieurs, dans l'industrie du vêtement à Fortaleza-Ceará. En tant que branche importante de la capitale du Ceará, l'industrie du vêtement, située principalement à la périphérie, compte un nombre expressif de travailleurs, principalement des femmes, ayant leur domicile sur le lieu de travail. Les changements intervenus dans cette branche industrielle avec la pandémie de Covid-19 et les actions de l'Etat sont analysés, principalement au niveau municipal pour garantir un revenu minimum et une production de masques pour la population locale, en utilisant les machines et l'industrie du vêtement instituées à Fortaleza. Comme méthodologie, la bibliographie liée au thème a été utilisée, l'analyse des données secondaires, suivie de la production de cet article.

\section{ÍNDICE}

Mots-clés: Circuits de l'économie. Industrie du vêtement. Covid19.

Keywords: Circuits of the economy. Clothing industry. Covid-19.

Palabras claves: Circuitos de la economía. Industria textil. COVID-19

Palavras-chave: Circuitos da economia. Indústria da confecção. Covid-19.

\section{AUTORES}

\section{MARLON CAVALCANTE SANTOS}

Doutor em Geografia pelo Programa de Pós- Graduação em Geografia da Universidade Federal do Ceará UFC. Professor da Rede Pública de Ensino de Fortaleza.

E-mail: marloncavalcante888@gmail.com 


\section{JOSÉ BORZACCHIELLO DA SILVA}

Professor Titular e Emérito da Universidade Federal do Ceará. Professor dos Programas de PósGraduação em Geografia da UFC e PUC-RIO, Pós-doutor em Geografia Humana pela Université de Paris IV - Sorbonne.

E-mail: borzajose@gmail.com

\section{ECIANE SOARES DA SILVA BEZERRA}

Doutora em Geografia pelo Programa de Pós-Graduação em Geografia da UniversidadeFederal do Ceará - UFC. Professora da Rede Pública de Ensino de Fortaleza.

E-mail:ecianess@gmail.com 